\title{
Current situation of newborn screening for congenital hypothyroidism in China
}

\author{
Juan Liu ${ }^{1}$, Yonglin Liu ${ }^{1}$ Xia $\mathrm{Li}^{2}$ and FuyongJiao*3 \\ ${ }^{1}$ Section of Children's, Health Care and Deptartment of Pediatrics, Shenmu County Hospital, Shaanxi Province 719300, China \\ ${ }^{2}$ Maternity and Child Care Centre of Shenmu County, Shaanxi Province 719300, China \\ ${ }^{3}$ Children's Hospital, Shaanxi Provincial People's Hospital of Xian Jiaotong University, Shaanxi Province 719300, China
}

Neonatal screening for congenital hypothyroidism is an effective way to improve birth population quality which is carried out at the international level for nearly 50 years and carried out in China for 30 years, it is one of the most successful public health measure. Domestic and international data show that the development and promotion of neonatal screening for congenital hypothyroidism disease has social benefit to prevent and improve the health of children with mental retardation, to improve the quality of the population born. Neonatal screening is gradually popular today, with improvement in detection technology, systems technology to enhance and improve diagnosis and treatment, Chinese new born screening for congenital hypothyroidism thyroid level will rapidly increase. For 50 years, newborn screening has saved many infant lives, or eliminating the occurrence of severe mental retardation and their physical development disorder, brought joy to millions of households. Status of Chinese newborn screening as follows.

\section{First, a brief history of neonatal screening for congenital hypothyroidism hypothyroidism}

China started to carry out newborn screening for congenital hypothyroidism hypothyroidism later. In 1981, Shanghai and Beijing carried out the first screening for congenital hypothyroidism disease. after Shanghai, Beijing exploring sexual conduct after neonatal screening, other cities have been carrying out this work. Neonatal screening for congenital hypothyroidism hypothyroidism gradually get the attention of government, national policy on neonatal screening were introduced: in October 1994, "People's Republic of China Maternal and Child Health Law" enacted, the provisions of "gradual development of neonatal diseases screening ", first in the form of regulations to determine the status of neonatal screening in disease prevention; in October 2001, China began the implementation of" People's Republic of China Maternal and Child Health Law Implementation Measures ", neonatal screening included in the technical services of maternal and child health; in 2004, the Ministry of Health issued a "neonatal screening technical specifications"; from June 1, 2009 implementation of "neonatal screening management approach", neonatal disease Screening management continue to be standardized. Currently, in most Chinese provinces to carry out newborn disease screening programs carried congenital hypothyroidism screening.

\section{Second, congenital hypothyroidism disease screening purposes and principles selected}

The purpose of neonatal screening for congenital hypothyroidism disease is to find serious, treatable disease in newborn children and apply appropriate interventions, and when to avoid or ameliorate adverse outcomes. Currently, tandem mass spectrometry can detect a variety of diseases, some patients may have substantially detected incurable disease. It was in favor of an incurable disease screening because families of children can benefit from a clear diagnosis, but not likely to last not know the cause of death.

Neonatal screening conditions are met briefly summarized as the following four points: (1) Early diagnosis can allow infants to benefit (even some incurable disease, in favor of the family as a whole can benefit infants and young children). (2) Benefits may be a reasonable balance between the economic and other costs. (3) There is a reliable detection method for neonatal screening. (4) There is a satisfactory operating system to handle diagnostic tests, consultation, treatment and follow-up of patients detected.

\section{Third, the prospect of congenital hypothyroidism disease screening}

Neonatal screening has become one of the most successful public health policy since the start. This is largely due to advances in analytical techniques biomarkers of disease areas, the importance of the active participation of parents and community organizations in promoting people to be aware of the importance of disease and treat disease screening method. Challenges neonatal screening is required to ensure that the medical profession does not exceed the range of detectable cognitive disorders or have adequate resources and facilities to manage these abnormalities of the disease [1-23].

In recent years, the development trend of international neonatal screening and gradually increased to the center with tandem mass spectrometry screening, a comprehensive cost-effectiveness analysis showed that tandem mass spectrometry is to reduce the cost of neonatal screening [24]. In addition to improving the efficiency of tandem mass spectrometry detection, the false-positive rate was significantly lower, not only the newborn disease screening techniques to a new level, has become the development direction of newborn screening for inherited metabolic diseases.

Correspondence to: Fuyong Jiao, Children's Hospital, Shaanxi Provincial People's Hospital of Xi, an Jiaotong University, China, Tel: ( 86) 029 -85368194, 85521331; ext: 2361(O), Mail Add: No.256 youyi West Rd.Xi,an 710068 China, E-mail: jiaofy@yeah.net, cnspcan@gmail.com

Received: November 09, 2015; Accepted: November 19, 2015; Published: November 21, 2015 
DNA microarray technology is currently used in neonatal screening so that the underlying disease due to mutations caused obtain early diagnosis, laid the foundation for further gene therapy. After the detection of biochemical markers have been mature during the traditional detect genetic diseases, gene level may be used as a further diagnosis, gene diagnosis such as congenital adrenal hyperplasia and cystic fibrosis [25]. To clear the gene mutations cause hereditary diseases, DNA testing is a priority level of inspection.

Application information integration system will rapidly integrate newborn screening laboratory data to the medical diagnosis and treatment agencies and public health authorities, effectively improve management efficiency at home and abroad which has become the focus of research [26]. Health authorities gradually strengthened the supervision of newborn screening systems, improve information, assess the service system of cooperation, cost-effectiveness analysis, knowledge of education and other aspects of the work [27]. Medical ethics of genetic testing and newborn screening expansion diseases involved cannot be ignored [28]. Screened children from childhood to adulthood, the system of medical care have gradually been concerned about.

\section{Fourth, congenital hypothyroidism disease screening technology development}

In recent years, a variety of analytical techniques have become routine laboratory neonatal screening technology used. Typically, screening strategies include determining an initial screening analytes and subsequent secondary sample testing analysis to improve its sensitivity and specificity. The initial screening technologies tandem mass spectrometry, colorimetric analysis test, fluorescence analysis test, enzyme or liquid chromatography and various immunological assays and other analysis, many of which can also be used for secondary analysis. With the improvement of existing technologies as well as new detection method of the present invention, it may be the number of disease detection screening will continue to increase.

\section{Fifth, the cause of congenital hypothyroidism $(\mathrm{CH})$}

Congenital hypothyroidism (congenital hypothyroidism, $\mathrm{CH}$ ) is the most common endocrine disease of newborns, congenital hypothyroidism is mainly due to thyroid aplasia or hypoplasia, may be present in the body to inhibit the growth of thyroid cells immune globulin; followed by thyroid hormone synthesis pathway enzyme defect (an autosomal recessive genetic disease); congenital hypothyroidism incidence in all ethnic groups of approximately 1/3000. China CH prevalence of approximately 49.2/100,000 [29,30]. Sick newborns usually appear normal, it is difficult to find in the case of the absence of screening, but the delay in treatment will lead to mental disorders, developmental delay.

The congenital hypothyroidism screening methods; $\mathrm{CH}$ : each screening laboratory according to their own conditions, were taken to radioimmunoassay (RIA), enzyme-linked immunosorbent assay (ELJSA), enzyme immunoassay fluorescence analysis (EFIA) and timeresolved immunofluorescence assay (DELFIA) and other methods Determination of filter paper blood spots of thyroid stimulating hormone (TSH) concentrations. After 1998, CH screening mainly high sensitivity DELFIA method, a few areas by ELISA and EFIA hair, RIA method has been basically no longer used. TSH positive cut value using 8-20 mIU/L range depending on the circumstances around the laboratory and kit, shear value than those who recalled review.

\section{Sixth, China congenital hypothyroidism situation}

China $\mathrm{CH}$ prevalence overall showed a rising trend, the prevalence was 24.5 in 1991 before/100,000, reached its peak in $200362.1 / 100,000$, by 2006 dropped to $57.8 / 100,000$. It is noteworthy that before $1998 \mathrm{CH}$ prevalence has stabilized at a lower level, with an average of 19.7/100,000 from 1998 to 2006, CH prevalence rate increased an average of 51.8/100 000 , mainly with improvement and recall of children suspected an increased detection methods. China's western region $\mathrm{CH}$ prevalence in the east and the Middle East, Central lowest prevalence.

\section{Seven, congenital hypothyroidism treatment and fol- low-up case}

$\mathrm{CH}$ is mainly due to thyroid congenital dysplasia, or many other factors by the presence of congenital defects which is caused by iodine deficiency and thyroid hormone synthesis. But for whatever reason, it must be made in thyroxine replacement therapy. Regular treatment is generally 2-3 years, the periodic review of thyroid function, thyroid $\mathrm{B}$ ultrasound or thyroid isotope scan, such as the withdrawal of temporary $\mathrm{CH}$ regular followup, such as permanent $\mathrm{CH}$ is to be lifelong replacement therapy, drug therapy is currently the main alternative L-thyroxine and thyroid is sodium, which is already widely used. Children with regular physical development, mental development and other assessments, and any time to adjust treatment.

\section{References}

1. Bickel H, Gerrard J, Hickmans Em (1953) Influence of phenylalanine intake on phenylketonuria. Lancet 265: 812-813. [Crossref]

2. Guthrie R, Susi A (1963) A simple phenylalanine method for detecting phenylketonuria in large populations of newborn infants. Pediatrics 32: 338-343. [Crossref]

3. Dussault JH, Coulombe P, Laberge C, Letarte J, Guyda H, et al. (1975) Preliminary report on a mass screening program for neonatal hypothyroidism. J Pediatr 86: 670674. [Crossref]

4. Pang S, Murphey W, Levine LS, Spence DA, Leon A, et al. (1982) A pilot newborn screening for congenital adrenal hyperplasia in Alaska. J Clin Endocrinol Metab 55: 413-420. [Crossref]

5. Crossley JR, Elliott RB, Smith PA (1979) Dried-blood spot screening for cystic fibrosis in the newborn. Lancet 1: 472-474. [Crossref]

6. Lees CM, Davies S, Dezateux C (2000) Neonatal screening for sickle cell disease. Cochrane Database Syst Rev: CD001913. [Crossref]

7. Wolf B, Heard GS (1991) Biotinidase deficiency. Adv Pediatr 38: 1-21. [Crossref]

8. Beutler E (1991) Galactosemia: screening and diagnosis. Clin Biochem 24: 293-300. [Crossref]

9. Millington DS, Kodo N, Norwood DL, Roe CR (1990) Tandem mass spectrometry: a new method for acylcarnitine profiling with potential for neonatal screening for inborn errors of metabolism. J Inherit Metab Dis 13: 321-324. [Crossref]

10. McCabe ER, Huang SZ, Seltzer WK, Law ML (1987) DNA microextraction from dried blood spots on filter paper blotters: potential applications to newborn screening. Hum Genet 75: 213-216. [Crossref]

11. Bradley DM, Parsons EP, Clarke AJ (1993) Experience with screening newborns for Duchenne muscular dystrophy in Wales. BMJ 306: 357-360. [Crossref]

12. Millington DS, Kodo N, Norwood DL, Roe CR (1990) Tandem mass spectrometry: a new method for acylcarnitine profiling with potential for neonatal screening for inborn errors of metabolism. J Inherit Metab Dis 13: 321-324. [Crossref]

13. Rinaldo P, Tortorelli S, Matern D (2004) Recent developments and new applications of tandem mass spectrometry in newborn screening. Curr Opin Pediatr 16: 427-433. [Crossref]

14. Green NS, Pass KA (2005) Neonatal screening by DNA microarray: spots and chips. Nat Rev Genet 6: 147-151. [Crossref]

15. Dobrowolski SF, Banas RA, Naylor EW, Powdrill T, Thakkar D (1999) DNA 
microarray technology for neonatal screening. Acta Paediatr Suppl 88: 61-64. [Crossref]

16. Targum SD, Lang W (2010) Neurobehavioral problems associated with phenylketonuria. Psychiatry (Edgmont) 7: 29-32. [Crossref]

17. Donati A, Vincenzi C, Tosti A (2009) Acute hair loss in phenylketonuria. J Eur Acad Dermatol Venereol 23: 613-615. [Crossref]

18. Williams RA, Mamotte CD, Burnett JR (2008) Phenylketonuria: an inborn error of phenylalanine metabolism. Clin Biochem Rev 29: 31-41. [Crossref]

19. Zhou YA, Ma YX, Zhang QB, Gao WH, Liu JP, et al. (2012) Mutations of the phenylalanine hydroxylase gene in patients with phenylketonuria in Shanxi, China. Genet Mol Biol 35: 709-713. [Crossref]

20. Blau N, van Spronsen FJ, Levy HL (2010) Phenylketonuria. Lancet 376: 1417-1427. [Crossref]

21. Gu X, Zhou J, Ye J (2002) Neonatal screening for congenital adrenal hyperplasia in Shanghai areas. Zhonghua Yu Fang Yi Xue Za Zhi 36: 16-18. [Crossref]

22. Levy HL (1998) Newborn screening by tandem mass spectrometry: a new era. Clin Chem 44: 2401-2402. [Crossref]

23. Bailey DB Jr, Gehtland L (2015) Newborn screening: evolving challenges in an era of rapid discovery. JAMA 313: 1511-1512. [Crossref]
24. Carroll AE, Downs SM (2006) Comprehensive cost-utility analysis of newborn screening strategies. Pediatrics 117: S287-295. [Crossref]

25. Fingerhut R, Olgemöller B (2009) Newborn screening for inborn errors of metabolism and endocrinopathies: an update. Anal Bioanal Chem 393: 1481-1497. [Crossref]

26. Downs SM, van Dyck PC, Rinaldo P, McDonald C, Howell RR, et al. (2010) Improving newborn screening laboratory test ordering and result reporting using health information exchange. J Am Med Inform Assoc 17: 13-18. [Crossref]

27. American College of Medical Genetics Newborn Screening Expert Group (2006) Newborn screening: toward a uniform screening panel and system--executive summary. Pediatrics 117: S296-307. [Crossref]

28. Dhondt JL (2010) Expanded newborn screening: social and ethical issues. J Inherit Metab Dis 33: S211-217. [Crossref]

29. Xu YH, Qin YF, Zhao ZY (2009) Retrospective study on neonatal screening for congenital hypothyroidism and phenylketonuria in China in the past 22 years. Zhonghua Er Ke Za Zhi 47: 18-22. [Crossref]

30. Jiao FY, Chen JP, Liu J, Li T, Liu FT (2015) An Analytical Study for Early Diagnosis and Treatment of Infants \& Children Suffering From Congenital Hypothyroidism in China. Int J Clin Endocrinol Metab 1: 017-021.20.

Copyright: $\odot 2015$ Liu J. This is an open-access article distributed under the terms of the Creative Commons Attribution License, which permits unrestricted use, distribution, and reproduction in any medium, provided the original author and source are credited. 